\title{
The Use and Benefits of Evaluation Framework Modules at the Canadian Foundation for Healthcare Improvement: Engaged Capacity Building and Collaborative Program Evaluation Planning
}

\author{
Julia Halar, Selma Didic \\ Canadian Foundation for Healthcare Improvement \\ Eden Amare \\ City of Toronto \\ Lise Labrecque \\ City of Ottawa \\ Margo Rowan \\ Principle Rowan Research and Evaluation
}

\begin{abstract}
The Canadian Foundation for Healthcare Improvement (CFHI) shares its experience using a collaborative approach to developing evaluation frameworks. CFHI introduced a series of four participatory workshop modules where technical and content experts co-design evaluation frameworks. This method leverages the expertise within the evaluation team to build organization-wide evaluation capacity. This practice note describes the modules, their delivery, and lessons learned. Participants' feedback suggests that evaluation modules are an effective strategy to strengthen the relationship and communication between evaluation experts and program staff.
\end{abstract}

Keywords: capacity building, co-creation, collaboration, evaluation planning, program evaluation

Résumé : La Fondation canadienne pour l'amélioration des services de santé (FCASS) partage une approche collaborative pour l'élaboration de cadres d'évaluation. La FCASS a présenté une série de quatre modules d'ateliers participatifs où des experts et expertes de contenu et techniques conçoivent ensemble des cadres d'évaluation. Cette méthode permet de tirer parti de l'expertise de l'équipe d'évaluation pour renforcer les capacités organisationnelles en évaluation. Cette note sur la pratique décrit les modules, la façon dont ils ont été présentés et les leçons tirées du processus. Les commentaires des participants et participantes laissent croire que les modules dévaluation constituent une stratégie efficace pour améliorer les relations

Corresponding author: Julia Halar, Canadian Foundation for Healthcare Improvement, 150 Kent St., Suite 200, Ottawa, ON, K1P 0E4; julia.halar@gmail.com 
et la communication entre les experts et expertes en évaluation et le personnel des programmes.

Mots clés : amélioration de la capacité, cocréation, collaboration, planification de l'évaluation, évaluation de programme

The Canadian Foundation for Healthcare Improvement (CFHI) works with partners to accelerate the identification, spread, and scale of proven healthcare innovations, with an emphasis on delivering better care closer to home and community. The pan-Canadian programs led by CFHI assist healthcare organizations to adapt, implement, and measure improvements in patient care, health, value for money, and the work life of healthcare providers. Such programs are formed with innovators, healthcare organizations, and other strategic partners, such as the Canadian Partnership against Cancer and the Canadian Frailty Network. These programs are aimed at particular areas of healthcare, including primary care, palliative care, and Indigenous health, to name a few. In addition to such programs, CFHI offers an executive training program to build the capacity of healthcare leaders across Canada to design and lead quality improvement solutions. CFHI is required to report on programming annually to its funder, Health Canada (HC), using a robust Performance Measurement Framework (PMF).

CFHI designed a series of four evaluation workshop modules both to strengthen evaluation and performance-measurement capacity and to address the increasing demand for evaluation support for its expanding programming. In addition, one of the driving factors in developing the module series was to help complement and balance CFHI's performance-measurement capacity with its program-evaluation function. In the past, CFHI focused on the development and implementation of outcome-measurement plans and systems for quality improvement. For example, reporting of end-of-program results was a strong focus when providing evidence of outcomes achieved and program effectiveness. The development of these modules sought to fill the process-evaluation gap to understand not only whether the program achieved results but also how and why it did so.

A key intended outcome of the workshop modules was to produce comprehensive evaluation frameworks, for each program, that consider program needs (e.g., goals, objectives, and context) and the organization-wide performancereporting obligations to $\mathrm{HC}$. The four workshop modules also implement common practices from the literature on planning and designing theory-based approaches to evaluation and assist programs to develop evaluation plans pertaining to the Government of Canada's Policy on Results (GOC, 2016) and Treasury Board of Canada's Directive on Results (TB, 2016), such as logic models (Mertens \& Wilson, 2019). The workshop modules are as follows: Creating a Program Logic Model, Building a Measurement Matrix, Planning for Data Collection, and Using and Disseminating Evaluation Findings to Key Stakeholders (see Table 1). Due to the diverse nature of the programming at CFHI, consideration of assumptions and context is critical, lending itself naturally to theory-based approaches to evaluation (GOC, 2012), which aims to "explain how (or why) programs work (or fail 
Table 1. Workshop modules: Key aims and sample activities

\begin{tabular}{|c|c|c|}
\hline Workshop module & Key aims & Sample activities \\
\hline $\begin{array}{l}\text { Creating a program } \\
\text { logic model }\end{array}$ & $\begin{array}{l}\text { - Co-create the development of } \\
\text { a program logic model } \\
\text { - Educate program staff about } \\
\text { the purpose and use of a } \\
\text { program logic model } \\
\text { - Open lines of communication } \\
\text { between program and } \\
\text { evaluation staff }\end{array}$ & $\begin{array}{l}\text { - Each program staff fills } \\
\text { out sticky notes for key } \\
\text { elements of the logic model } \\
\text { - Hold group discussion/ } \\
\text { interactive activity to } \\
\text { move sticky notes and add } \\
\text { whiteboard comments } \\
\text { regarding overlap or gaps } \\
\text { in a model's logic }\end{array}$ \\
\hline $\begin{array}{l}\text { Building a } \\
\text { measurement } \\
\text { matrix }\end{array}$ & $\begin{array}{l}\text { - Co-create a measurement } \\
\text { matrix } \\
\text { - Educate program staff } \\
\text { on the key elements of a } \\
\text { measurement matrix and } \\
\text { define key terms (e.g., } \\
\text { indicators) } \\
\text { - Identify key evaluation } \\
\text { questions } \\
\text { - Select minimal, meaningful, } \\
\text { and manageable indicators }\end{array}$ & $\begin{array}{l}\text { Hold interactive sticky- } \\
\text { note activity to ensure that } \\
\text { indicators for all previously } \\
\text { determined program } \\
\text { outputs and outcomes have } \\
\text { been identified }\end{array}$ \\
\hline $\begin{array}{l}\text { Planning for data } \\
\text { collection }\end{array}$ & $\begin{array}{l}\text { - Co-create a data collection } \\
\text { plan } \\
\text { - Identify key dates/methods/ } \\
\text { resources for data collection }\end{array}$ & $\begin{array}{l}\text { Hold interactive data- } \\
\text { collection timeline activity } \\
\text { using sticky notes }\end{array}$ \\
\hline $\begin{array}{l}\text { Using and } \\
\text { disseminating } \\
\text { evaluation } \\
\text { findings to Key } \\
\text { Stakeholders }\end{array}$ & $\begin{array}{l}\text { - Co-create a plan for the } \\
\text { use and dissemination of } \\
\text { evaluation findings } \\
\text { - Identify key stakeholders, } \\
\text { align stakeholder interests } \\
\text { with program outcomes, and } \\
\text { evaluation questions } \\
\text { - Identify opportunities to } \\
\text { engage key stakeholders } \\
\text { - Determine appropriate timing } \\
\text { and methods of dissemination }\end{array}$ & $\begin{array}{l}\text { - Hold interactive sticky- } \\
\text { note activity where each } \\
\text { workshop participant } \\
\text { identifies potential } \\
\text { intended users and use of } \\
\text { evaluation findings }\end{array}$ \\
\hline
\end{tabular}

Note. Table 1 includes a generic description; variations/modifications have occurred based on participant needs, program goal, and timelines, etc.

to work)" (Lemire, Whynot, \& Montague, 2019, p. 422). CFHI also drew from literature on participatory approaches to theory-based evaluation and targeted engagement from various stakeholders (Lemire et al., 2019, p. 417). Furthermore, the workshops employ adult-learning strategies to maximize capacity building. This practice note describes the modules, their delivery, and lessons learned. 


\section{EVALUATION WORKSHOP MODULES}

The workshops combine the expertise of both program (content) and evaluation (technical) staff to create mutually valued evaluation tools (Moreau, Peddle, \& Eady, 2015). These workshops leverage internal evaluators as knowledge brokers, as capacity builders, and as "an enduring corporate resource" that is useful in a number of contexts (Love, 1991, p. 5). The four modules last approximately two to three hours and use an adult-learning approach to help strengthen the evaluation capacity of staff. Present are two to five program staff and two to three evaluation staff, one of whom facilitates the sessions. Generally, there are three to four weeks between each module, allowing time to co-create various products of relevance to subsequent modules.

In an engaging and participatory manner, the modules aim to support teams to plan their evaluation work at the start of each program, design methods and data-collection strategies, and foster the use of evaluation findings. Furthermore, the collaborative nature of the workshops builds upon the principles that guide Collaborative Approaches to Evaluation (CAE) (Cousins \& Earl, 1995; Cousins, Whitmore, Shulha, Al Hudib, \& Gilbert, 2015). CAE is recognized for fostering long-lasting and transferable evaluation capacity and skills (Whitmore, Al Hudib, Cousins, Gilbert, \& Shulha, 2017). The workshops align with elements of collaborative inquiry (Edey \& Newton, 1995), as CFHI encourages content experts to participate in the learning process, and "involve evaluation 'experts' in new ways while maintaining acceptable standards of practice" (Edey \& Newton, 1995, p. 4). The workshops are designed to promote evaluative thinking (Vo \& Archibald, 2018), foster stronger relationships, promote participatory processes, and increase the use of evaluation findings, among other principles of CAE. Moreover, the workshops help to strengthen evaluation capacity, which is defined as "the intentional work to continuously create and sustain overall organizational processes that make quality evaluation and its use routine" (Stockdill, Baizerman, \& Compton, 2002, p. 8). For example, the workshops use the capacity of the internal evaluators while simultaneously providing an opportunity for skill development and refinement in at least three of the categories of professional competencies from the Canadian Evaluation Society: technical, situational, and interpersonal practice (CES, 2018).

The four workshop modules were first introduced at CFHI in November 2017. Initially, modules were piloted with one program team, resulting in minor revisions to workshop duration, type of interactive activities, and timing of tool development. Other teams, at the beginning stages of their program, were then invited to participate. To date, the modules have been facilitated with eight programs (in some cases the whole suite of workshops and in other cases only the most suitable modules). Participants are provided with a certificate of completion at the end of the four modules. All new programs are encouraged to participate in the modules, and evaluation support is embedded throughout the entire life cycle of the program-from the design phase through to results reporting. Creating an evaluation framework is not recommended for short-term programming (i.e., less 
than one year) or for those programs that do not intend to conduct an evaluation based on their theory of change.

Workshops are generally delivered using a common format with minor adaptations. Pre-reading materials are provided to participants prior to each workshop. These materials set the stage for each workshop topic by providing brief background information, including definitions and examples. Each workshop begins by identifying the needs and expectations of participants, addressing any questions or concerns from participants, highlighting the importance of program staff as content experts, and offering "technical" expertise of evaluation staff. This introduction encourages participants to actively engage throughout the workshop, which is critical for the success of collaborative approaches (Whitmore et al., 2017). Subsequently, the evaluation lead provides a short presentation on relevant program-evaluation content (e.g., logic model components) to give participants the background information they need to co-create the deliverable or product resulting from each module (e.g., measurement matrix). Interactive activities engage all participants and stimulate evaluative and critical thinking. Activities have participants "up on their feet," typically using a whiteboard, markers, and sticky notes. Workshops require strong facilitation skills to guide the discussion, keep participants on task, and maximize time together for collaboration and cocreation.

\section{PERCEIVED BENEFITS}

For a quality-improvement organization, feedback about the modules is continuously gathered and integrated into the development of subsequent workshops. This aligns with the organization's adopted rapid cycle of quality improvement: the plan, do, study, act (PDSA) cycle (IHI, 2018). PDSAs are used throughout the work, including curriculum development, program delivery, evaluation, and strategic planning. Feedback on the process and content of the modules is obtained and measured after the workshops in many ways, such as post-workshop paper surveys completed by all workshop participants, requests for unstructured verbal feedback from participants after all workshops, and at an annual all-staff learning event and meetings with facilitators to debrief on the workshops. Technical and content experts jointly co-design the revised evaluation content for future modules.

Feedback from program staff suggested that evaluation modules were an effective strategy to help strengthen the relationships and communication between evaluation experts and program staff. The workshops activated evaluative thinking around program outcomes, indicators, data collection, and dissemination through the planned interactive activities. Participants reported that they highly value the dedicated time and space to brainstorm, discuss, and reflect, which gave way to a deeper shared understanding of the program-a known success factor of collaborative evaluation approaches (Whitmore et al., 2017). During each workshop, "a-ha” moments were frequently celebrated, such as gaps in logic, 
clarity around outcomes, new considerations for program elements, identifying additional key stakeholders, and innovative ways to collect data or share results, to name a few.

The workshops were found to strengthen the capacity to conduct evaluations in the following ways:

- leveraging expertise among program-evaluation and performancemeasurement staff;

- $\quad$ providing an opportunity for professional development for staff across the organization;

- integrating evaluation and performance-measurement requirements into evaluation plans;

- $\quad$ identifying minimal, meaningful, and manageable data sets (MMMDs);

- identifying ongoing data-collection needs;

- developing evaluation tools;

- distinguishing the need for external consultants or supporting resources; and

- $\quad$ promoting information sharing.

\section{LESSONS LEARNED}

Several years of designing, delivering, and refining the workshop series and cocreating the resulting evaluation frameworks have yielded many "lessons learned." CFHI looked to evaluation findings (i.e., completed post-session evaluations), their own reflective practice as evaluators, and insights from program participants to arrive at the following lessons learned (Patton, 2014):

1. It is beneficial to engage staff early in evaluative thinking. The collaborative nature of the workshops provides an early opportunity for all program and evaluation staff to "get on the same page" and jointly discuss underlying programmatic assumptions, context, key stakeholders, history, evaluation-related budget requirements, and program-design elements.

2. The workshops provide the evaluation team with a comprehensive understanding of all programming taking place across the organization, which allows the evaluation team to determine how they can deploy their resources most efficiently and effectively.

3. The workshops can be leveraged to facilitate an assessment of program evaluability, as the collaborative discussions highlight barriers to obtaining MMMDs. For example, program staff identified scheduled stakeholder roundtable meetings or webinars, which served as an ideal opportunity to collect relevant data. This information helped populate a measurement matrix and data-collection manual for the program's evaluation framework. 
4. It is important to mindfully use situational competencies during the planning and execution of the workshop modules. For example, due to the various time-constraints, the workshop facilitators needed to identify "stakeholders' needs and their capacity to participate while recognizing, respecting, and responding to aspects of diversity" (CES, 2018).

5. When developing and designing the modules, it is important to be open and responsive to the needs of the organization. For example, initially, three modules were ending with a data-collection plan. However, program and evaluation staff agreed that a fourth module (Using and Disseminating Evaluation Findings to Key Stakeholders) would support teams in planning the delivery of evaluation findings to the appropriate stakeholders at the most relevant times (e.g., scheduled quarterly meetings). This aligns with utilization-focused approaches to evaluation (Patton, 2008) and was wholeheartedly supported by CFHI's knowledge translation and communications staff, who helped develop the content of the new module. The needs of CFHI will continue to be monitored and modules may be expanded, or additional modules may be developed in the future.

6. Accommodations were needed with respect to the number and style of modules delivered. Some modules that may have previously been delivered in workshop format may now be delivered in a one-on-one consultation between the evaluation and program leads, in part due to time constraints for program staff. Modules may not always be delivered sequentially. For example, Module 4 on using and disseminating findings may be delivered sooner, depending on the needs of the program and where it is in its lifecycle.

7. Collaborating with program staff involves navigating the variability of program evaluation needs across programs and the frequent humbling experience of saying, "I don't know, let me get back to you," as evaluators created many opportunities for personal growth and development. Developing evaluation frameworks in such an open context requires one to hone one's interpersonal skills, become very adaptable, and practice patience (with the process, the participants, and oneself). The evaluators were challenged out of their knowledge "comfort zone" when collaborating with programs to develop evaluation frameworks that best suited the program's needs. This process helped identify areas for future professional development.

These lessons learned have benefitted CFHI's staff, including its evaluators, program specialists, communications and knowledge translation teams, and the quality-improvement teams in the field, supported by CFHI, by

- creating a common understanding of how the programs are implemented and of the contextual factors that may affect implementation;

- developing realistic evaluation plans that are comprehensive yet also flexible enough to meet the needs of program staff; and 
- creating synergy among the evaluation, knowledge translation, and communication efforts and using and disseminating evaluation findings throughout the lifecycle of the quality-improvement initiatives.

\section{CONCLUSION}

Co-creating evaluation frameworks by evaluation and programming specialists has proven extremely successful at CFHI. The workshop modules and final evaluation frameworks have helped CFHI's program staff learn more about evaluation, how to share the results, and how to use evaluation findings to tell the story behind their programming efforts. It has enhanced the ability of evaluation staff to be open and adaptable in their approach to learning about and constructing evaluation frameworks. Building evaluation frameworks in this way has brought evaluation and programming teams together and deepened their understanding and appreciation of each other's role and value at CFHI. This consultative and participatory strategy offers a viable method for organizations who seek to strengthen their internal evaluation capacity.

\section{REFERENCES}

Canadian Evaluation Society (CES). (2018, November 2). Competencies for Canadian evaluators. Retrieved from https://evaluationcanada.ca/competencies-canadianevaluators

Cousins, J. B., \& Earl, L. M. (1995). The case for participatory evaluation: Theory, research, practice. In J. B. Cousins and L. M. Earl (Eds.), Participatory evaluation in education: Studies in evaluation use and organizational learning (pp. 3-18). London, England: Falmer Press.

Cousins, J. B., Whitmore, E., Shulha, L., Al Hudib, H., \& Gilbert, N. (2015). Principles to guide collaborative approaches to evaluation. Retrieved from https://evaluationcanada. $\mathrm{ca} /$ sites/default/files/20170131_caebrochure_en.pdf

Edey, S., \& Newton, P. (1995). Collaborative inquiry: Integrating evaluation into the workplace. In A. J. Love (Ed.), Evaluation methods sourcebook II (pp. 4-16). Ottawa, ON: CES. Retrieved from https://evaluationcanada.ca/secure/sb2_ch1.pdf

Government of Canada (GOC). (2012, October 25). Theory-based approaches to evaluation: Concepts and practices. Retrieved from https://www.canada.ca/en/treasury-boardsecretariat/services/audit-evaluation/centre-excellence-evaluation/theory-basedapproaches-evaluation-concepts-practices.html

Government of Canada (GOC). (2016, July 1). Policy on results. Retrieved from https:// www.tbs-sct.gc.ca/pol/doc-eng.aspx?id=31300\&section=html

Institute for Healthcare Improvement (IHI). (2018, October 31). How to improve. Retrieved from http://www.ihi.org/resources/Pages/HowtoImprove/default.aspx

Lemire, S., Whynot, J., \& Montague, S. (2019). How we model matters: A manifesto for the next generation of program theorizing. Canadian Journal of Program Evaluation, 33(3), 414-433. https://doi.org/10.3138/cjpe.53070 
Love, A. J. (1991). Internal evaluation: Building organizations from within. Newbury Park, CA: Sage.

Mertens, D. M., \& Wilson, A. T. (2019). Program evaluation theory and practice (2nd ed.). New York, NY: The Guildford Press.

Moreau, K. A., Peddle, B., \& Eady, K. (2015). The promise of participatory evaluation in family-centered rehabilitation settings: A qualitative study. Journal of MultiDisciplinary Evaluation, 11(25), 1-13. Retrieved from http://journals.sfu.ca/jmde/index.php/ jmde_1/article/view/406

Patton, M. Q. (2008). Utilization-focused evaluation (4th ed.). Thousand Oaks, CA: Sage.

Patton, M. Q. (2014). Evaluation flash cards: Embedding evaluative thinking in organizational culture. St. Paul, MN: Otto Bremner Trust.

Stockdill, S. H., Baizerman, M., \& Compton, D. W. (2002). Toward a definition of the ECB process: A conversation with the ECB literature. New Directions for Evaluation, 2002(93), 7-26. https://doi.org/10.1002/ev.39

Treasury Board of Canada (TB). (2016, July). Directive on results. Retrieved from https:// www.tbs-sct.gc.ca/pol/doc-eng.aspx?id=31306\&section=html

Vo, A. T., \& Archibald, T. (2018). New directions for evaluative thinking. Evaluative Thinking. New Directions for Evaluation, 2018(158), 139-147. https://doi.org/10.1002/ ev.20317

Whitmore, E., Al Hudib, H., Cousins, J. B., Shulha, L. M., \& Gilbert, N. (2017). Reflections on the meaning of success in collaborative approaches to evaluation: Results of an empirical study. Canadian Journal of Program Evaluation, 31(3), 328-349. https:// doi.org/10.3138/cjpe.335

\section{AUTHOR INFORMATION}

Julia Halar is a pragmatic program evaluator who holds a Master's degree in education. She seeks opportunities to practice evaluation and performance measurement in various learning environments. Currently an Evaluation Lead at the Canadian Foundation for Healthcare Improvement (CFHI), Julia leads the development and implementation of evaluation frameworks for quality improvement initiatives such as EXTRA (Executive Training Program). In addition, Julia is passionate about building evaluation capacity within organizations and individuals; a considerable amount of her recent work was the development and facilitation of evaluation framework modules at CFHI. She is a life-long learner, eager to grow professionally and excited to explore new and emerging trends in evaluation and performance measurement, and she is pursuing the CE designation with the Canadian Evaluation Society.

Eden Amare is an evaluator who specializes in public health and social services. Formerly, she was an Evaluation Analyst at the Canadian Foundation for Healthcare Improvement (CFHI). In this role, she evaluated quality-improvement collaboratives and participated in both the development and facilitation of evaluation capacity-building workshops. She also possesses experience as a Program Evaluator at Toronto Public Health, where she evaluated various communicable disease control programs in areas such as health informatics, sexual health, and infection control. Eden currently works as a Policy Development Officer with the Shelter, Support and Housing Administration (SSHA) division of the City of Toronto, 
where she leads evaluations and quality assessments of services. Eden holds a Master of Health Evaluation degree from the University of Waterloo and currently sits on the Board of Directors for the Canadian Evaluation Society-Ontario Chapter.

Lise Labrecque has led over 20 evaluations and research projects in organizations of all sizes in her 30 years' experience in the Canadian healthcare sector (public health, primary care, and community health). Formerly the Senior Evaluation Lead at the Canadian Foundation for Healthcare Improvement, Lise supported teams to evaluate quality-improvement projects. She was the lead evaluator of Paramedics and Palliative Care: Bringing Vital Services to Canadians and Bridge-to-Home, using utilization-focused and collaborative approaches to evaluation. Lise is currently a Learning and Development Specialist with the City of Ottawa and will soon be leading a learning needs assessment of the City's 17,000 employees.

Selma Didic leads the development, implementation, and reporting of CFHI's results framework, including CFHI's Performance Measurement Framework and its corporate dashboard. She manages and oversees the tracking of metrics to measure CFHI's progress in achieving its strategic objectives and analyzes data to tell the story of the impact that CFHI's work is having. Selma has also led evaluations for CFHI quality-improvement collaboratives and provides advice and support to internal program teams across CFHI to develop and implement their evaluation frameworks. Selma has designed and conducted qualitative and quantitative research in a variety of settings for almost ten years. She has published on topics such as economic growth, healthcare, and travel and tourism.

Margo Rowan is a creative, authentic, highly experienced, and credentialed evaluator. At the time of writing, she was the Director of Evaluation and Performance Measurement at the Canadian Foundation for Healthcare Improvement (CFHI). She runs a successful consulting business with a team of trusted colleagues. She has an extensive background in all facets of program evaluation and research design, implementation, data collection, analysis, and publication. Her special interests are in developing performance-measurement frameworks, conducting qualitative and mixed method studies, and writing for publication. She enjoys mentoring staff and applying the evidence on evaluation and performance measurement to the work she does. 